\title{
La reciprocidad puesta a prueba. Hacia una fenomenología social del cambio climático en sociedades pastoriles del sur andino peruano
}

AdHemir Flores Moreno

Pontificia Universidad Católica del Perú

Resumen: Dado que las sociedades pastoriles de los Andes peruanos pocas veces participan en los debates científicos y políticos sobre el cambio climático, este artículo pretende explicitar y dar cuenta de los idiomas de creencias, las significaciones y las vivencias de los principales afectados, desde una aproximación filosófica y antropológica. En una época de crisis ecológica, no solo se pone en cuestión el mundo de certidumbres o las experiencias de sentido de los pastores de altura, sino que estos también encuentran una ocasión propicia para la crítica de las relaciones de reciprocidad en la totalidad de lo existente, así como para ofrecer respuestas a sus diversas interrogantes desde diferentes paradigmas interpretativos o juegos de lenguaje. Con la misma fuerza con que los relatos de los campesinos permiten mostrar que crisis, crítica y creación van esencialmente unidas, emerge la necesidad de poner límites a la pretensión cientificista o dogmática de reducir el debate sobre el cambio climático a decisiones cerradas de grupos de expertos o de centros de poder autonomizados, al margen de todo proceso político de discusión y de diálogo con los principales afectados. De allí resulta la exigencia ética de iniciar procesos de democratización que puedan dar voz a los marginados y los incluya en los procedimientos de deliberación pública sobre el cambio climático, mediante la reciprocidad, la cooperación social y los intercambios simbólicos en pie de igualdad.

Palabras claves: sociedades pastoriles, paradigmas interpretativos, reciprocidad, intercambios simbólicos, democratización

Abstract: Given that the pastoral societies of the Peruvian Andes have seldom participated in scientific and political debates about climate change, this paper aims to explain and account for the languages of beliefs, meanings, and experiences of those principally affected from a philosophical and anthropological approach. In a time of ecological crisis, not only is the world of certainties or the significant experiences 
of the highland shepherds put into question, but also there is an opportunity for the critique of the relationships of reciprocity in the totality of what exists, offering answers to various inquiries through different interpretative paradigms or language games. With the same strength with which the accounts of the peasants are able to show that crisis, critic, and creation go essentially hand-in-hand, there rises the need to establish limits to the scientific or dogmatic pretention of reducing the debate about climate change solely to closed decisions of expert groups or autonomous power centers, apart from all political process of discussion and dialogue with those mainly affected. Thence comes the ethical demand to initiate processes of democratization that can give a voice to the marginalized and include them in the procedures of public deliberation about climate change by means of reciprocity, social cooperation, and symbolic exchanges on equal standing.

Keywords: pastoral societies, interpretative paradigms, reciprocity, symbolic exchanges, democratization

Es materia de consenso en la comunidad científica que el cambio climático es un proceso de alcance planetario que ya está ocurriendo, especialmente en países como el Perú ${ }^{75}$. Si bien se trata de un proceso de largo plazo caracterizado por la incertidumbre y la inseguridad, los científicos aportan con conceptos, modelos y categorías que sirven para ponderar tanto las evidencias y los impactos del cambio climático como las opciones de mitigación y adaptación en contextos determinados ${ }^{76}$, mientras que la comunidad política recurre a la ciencia para informarse empíricamente sobre el cambio climático y adoptar estrategias o técnicas políticas para afrontarlo. Se sabe que las sociedades pastoriles alto andinas, que a lo largo del tiempo han logrado desarrollar una

75 Cf. Comunidad Andina de Naciones, El Cambio Climático no tiene fronteras. Impacto del Cambio Climático en la Comunidad Andina, Lima: Comunidad Andina/Ministerio del Medio Ambiente y Medio Rural y Marino/AECID, 2008; Adger, W.N. y N. Brooks, "Does Global Environmental Change Cause Vulnerability to Disaster?", en: Pelling, M. (ed.), Natural Disasters and Development in a Globalizing World, Londres: Routledge, 2003, p. 35.

76 Cf. Huggel, C., W. Haeberli, A. Kääb, M. Hoelzle, E. Ayros y C. Portocarrero, Assessment of Glacier Hazards and Glacier Runoff for Different Climate Scenarios Based on Remote Sensing Data: A Case Study for a Hydropower Plant in the Peruvian Andes, Zurich: Universidad de Zurich, 2003; Francou, B., P. Ribstein, P. Wagnon, E. Ramirez y B. Pouyaud, "Glaciers of the Tropical Andes: Indicators of the Global Climate Variability”, en: Huber, U.M., H.K.M. Bugmann y M.A. Reasoner (eds.), Advances in Global Change Research, XXIII (2005); Vuille, M., B. Francou, P. Wagnon, J. Juen, G. Kaser, B. Mark y R. Bradley, "Climate Change and Tropical Andean Glaciers: Past, Present and Future”, en: Earth-Science Reviews, LXXXIX (2008), pp. 79-96. 
alta compenetración y conocimiento de su medio ecológico, son unas de las principales afectadas por este riesgo global, aun cuando son las que menos han contribuido a este problema ${ }^{77}$. Sin embargo, estas poblaciones son raramente tomadas en cuenta en las diversas discusiones académicas y políticas sobre el cambio climático: o bien los pastores de alta montaña son completamente prescindibles para la comunidad científica y política, o bien sus relatos o sus vivencias son consideradas básicamente para corroborar o ampliar verdades científicas y legitimar decisiones políticas determinadas con anterioridad. Y si bien existen investigaciones científicas que cada vez confieren una mayor importancia a los relatos y a las iniciativas de las poblaciones locales para afrontar el cambio climático, son poco hegemónicas en los debates científicos sobre él y tienen una escasa influencia en las políticas públicas que países como el Perú han adoptado en los últimos años ${ }^{78}$. Esto quiere decir que las ciencias naturales llevan la voz cantante en lo que se sabe hasta ahora sobre el cambio climático, mientras que la sociedad política es la que se arroga el derecho de decidir qué hacer frente a esta crisis ecológica, al margen de los fines, las constituciones de sentido o las experiencias del mundo de los principales afectados ${ }^{79}$.

Este artículo surge de una cierta hermenéutica de la sospecha por esta situación de hecho y, como respuesta, busca describir, elucidar o explicitar aquellas creencias y constituciones de sentido de los pastores de alpaca frente al cambio climático, desde las condiciones reales de sus mundos de la vida en los Andes centrales. Hacemos esto porque creemos que ellos tienen algo que decirnos sobre la "crisis de sentido" que entraña el cambio climático y sobre las "responsabilidades éticas" de la humanidad contemporánea en ese contexto. Para ello, trataremos de hacer dialogar algunas de las principales hipótesis de

77 Cf. Gitay, H., S. Brown, W. Easterling y B. Jallow, "Ecosystems and Their Goods and Services", en: McCarthy, J., O.F. Canziani, N.A. Leary, D.J. Dokken y K. White (eds.), Climate Change 200I: Impacts, Adaptation, and Vulnerability. Contribution of Working Group II to The Third Assessment Report of the Intergovernmental Panel on Climate Change, Cambridge: Cambridge University Press, 200I, pp. 237-342.

78 Cf. Cruikshank, J., Do Glaciers Listen? Local Knowledge, Colonial Encounters and Social Imagination, Vancouver: UBC Press, 2005; Macchi, M. y G. Oviedo, "Indigenous and Traditional Peoples and Climate Change Issues Paper”, en: International Union for Conservation of Nature 2008. Available in: http://cmsdata.iucn.org/downloads/indi- genous_peoples_climate_change. pdf.

79 Cf. Namihas, S., Conferencia sobre cambio climático - COP 20: las perspectivas y los temas críticos para el Perú, Lima: IDEI/KAS/SPDA, 2014. 
la fenomenología de Husserl, la filosofía del lenguaje de Wittgenstein y la teoría de los intercambios simbólicos de Mauss con una investigación etnográfica realizada por nosotros en algunas comunidades pastoriles de Cusco entre el 2009 y el $2010^{80}$. El diálogo intercultural supuso una relación de escucha activa y metódica con nuestros interlocutores en sus diferentes situaciones de referencia, tan alejada de la entrevista no dirigida como del dirigismo del cuestionario. Eso significó la disponibilidad total a la perspectiva de la persona entrevistada y la sumisión a la singularidad de su historia particular, que pueden conducir, por una suerte de mimetismo más o menos dominado, a adoptar su lenguaje y a entrar en sus visiones, en sus sentimientos, en sus pensamientos ${ }^{81}$.

\section{§ 1. Una crisis de sentido más allá de naturaleza y sociedad}

Las comunidades seleccionadas para este estudio presentan algunas características generales que puede ser útil destacar. Quillihuara y Sausaya Central son dos comunidades pastoriles que están ubicadas en la provincia de Canas, región del Cusco, con alturas que oscilan entre los 3,750 y los 5,800 m.s.n.m. La primera comunidad está integrada por 48 familias quechua hablantes; la segunda, por 80 .

Las estrategias de reproducción social de los mundos de la vida de estas comunidades pastoriles dependen, principalmente, del manejo escalonado de diversos pisos ecológicos y de múltiples zonas de producción ${ }^{82}$. Cada familia de pastores cuenta, por lo general, con acceso a dos áreas de tierras,

80 Las entrevistas, que analizaremos a lo largo del presente artículo, fueron realizadas por el autor originalmente en quechua y publicadas, en una versión más amplia, en un trabajo anterior. Sin embargo, la interpretación y el análisis de discursos que hacemos aquí de algunos fragmentos seleccionados, cuya traducción hemos vuelto a revisar, son completamente inéditos. Véase: Flores Moreno, A. y G. Valdivia, Impactos de la variabilidad en los sistemas productivos rurales y en las condiciones de vida y desarrollo campesinos: una visión desde la población rural de Cusco y Apurímac. Informes de la microcuenca Huacrahuacho (Cuzco) y Mollebamba (Apurímac), Zurich/ Lima/Cusco: Agencia Suiza para la Cooperación y el Desarrollo (COSUDE)/Ministerio del Ambiente (MINAM)/Programa de Adaptación al Cambio Climático (PACC)/Centro Bartolomé de las Casas, 2010; disponible en: www.paccperu.org.pe/estudios_locales.html.

81 Cf. Bourdieu, P., La misère du monde, París: Editions du Seuil, 1993, pp. 1393-1394.

82 Cf. Orlove, B.S., Alpacas, Sheep and Men, Nueva York: Academic Press, 1977; Gose, Peter, Work, Class and Culture in Huaquirca, a Village in the Southern Peruvian Andes, tesis de Ph.D, Londres: London School of Economics, 1986; Mayer, E., The Articulated Peasant. Household Economies in the Andes, Oxford: Westview Press, 2002. 
situadas en dos zonas diferenciadas, alta y baja, que permiten aprovechar mejor la estacionalidad de las lluvias y, por tanto, el ciclo de reproducción de los pastos que sirven de alimento para el ganado. De acuerdo con ello, los pastores suelen contar con dos lugares de residencia, una casa principal y una cabaña, entre las que alternan su residencia durante el año. En la primera, permanecen más tiempo cada año (de setiembre a abril) y es el lugar en el que se guardan los alimentos necesarios para la alimentación de la familia durante todo el año, las herramientas, las medicinas para los animales, entre otras cosas domésticas. Por otro lado, la cabaña es la residencia que los pastores habitan durante los otros meses del año (de mayo a setiembre) y llevan solo lo necesario para permanecer ahí durante ese período.

Los pastores de altura ubican a los apus, a la montaña divinizada, en la cúspide más alta de sus sistemas de creencias. El apu o divinidad local es el centro del sistema de referencias de los pastores: de él depende la disponibilidad de especies y animales, la domesticación de esas especies por parte de los pastores $y$, por tanto, las condiciones de reproducción social de las sociedades pastoriles. El apu es una divinidad "ordenadora o animadora del mundo" (kamachiq) y, a la vez, un "pastor sobrenatural de hombres" (runa michiq) y "guardián vigilante" 83 . Los apus no son "creadores" absolutos del universo: son "ordenadores" de la totalidad de lo existente. El apu es un agente o un actor en el sentido de que ordena el mundo. Los apus insuflan el ánimo (samay) a todos los seres vivos; es decir, transmiten una fuerza activa, en movimiento, que hace posible su propia realización. Se puede decir que samay (respirar) y kamay (ordenar) son expresiones con significados intercambiables ${ }^{84}$. En un espacio sacralizado como el de las altas montañas, el ámbito de lo profano es pequeño ${ }^{85}$.

Esto impone una serie de intercambios simbólicos entre los pastores de altura y la divinidad local que combinan don, obligación y libertad. Se trata, en todos

83 Cf. Casaverde Rojas, J., "El mundo sobrenatural en una comunidad”, en: Allpanchis Phuturinqa, II (1970), pp. I2I-243; Sánchez Garrafa, R., “Espacios y estructuras religiosas en los mitos del Ausangate”, en: Anthropologica, XIII (1995).

84 Cf. Ricard Lanata, X., “'El irracional es el otro’: los mecanismos de interpretación en antropología”, en: Anthropologica, XXIII (2005), pp. 5-4I.

85 Cf. Rösing, I., "La deuda de ofrenda: un concepto central de la religión andina”, en: Revista Andina, XII, No. I (1994), p. 195. 
los casos, no de una relación impersonal o abstracta, sino de una relación interpersonal y familiar, una relación de complicidad y solidaridad. Los bienes que otorga la divinidad, en cierto sentido, representan un atentado contra la libertad de los campesinos que lo reciben: la divinidad obliga a devolver, y a devolver más; crea unas obligaciones, unos deberes, unos actos simétricos de regalar y recibir. Los campesinos pueden rechazar esa alianza, ese contrato, pero no tienen derecho ni están interesados en rechazarlo. Además, la prestación total de los apus no solo impone la obligación de recibirlos, sino también la obligación de devolverlos mediante el culto, mediante el homenaje a la divinidad local, representado por los ritos propiciatorios, los pagos y las t'inkas. Esos intercambios mezclan, por tanto, libertad y obligación: no restituir el don puede ser peor que no haber recibido nada, no dar nada a otros puede ser peor para uno mismo en tiempos difíciles. No hay allí libertad de opción, solo de decisión; la libertad deja de ser extraña a la obligación, y esta a aquella. La libertad es una especie de destino para las partes de los intercambios: como reza una expresión latina, "el destino guía a quien se somete y arrastra al que se resiste".

El culto es el medio por el cual los campesinos indígenas renuevan reciprocidades y lealtades con sus antepasados, con los espíritus y con sus dioses locales, para reorientar la suerte de su existencia en favor suyo y evitar, así, las malas cosechas, las rivalidades, los celos, las inclemencias del tiempo, los desastres naturales y la desestructuración del orden social. No hacerlo, no cumplir la deuda de reciprocidad, significa suspender la alianza, el vínculo espiritual, y exponer la existencia social a las consecuencias arbitrarias de esa falta de reciprocidad. Como dice Mauss: “(...) son ellos [los dioses y los espíritus de los muertos] los verdaderos propietarios de las cosas y de los bienes del mundo. Era con ellos con quienes era más necesario intercambiar y más peligroso no hacerlo" ${ }^{86}$. En efecto, en esa economía del don no solo hay una mezcla de libertad y obligación, sino también de interés y desinterés; así como los dones no son plenamente libres, tampoco son realmente desinteresados. En su mayoría se trata de prestaciones y contraprestaciones realizadas con vistas no solo a pagar servicios y determinadas cosas, sino también para mantener una alianza provechosa que ni siquiera puede ser rechazada. De en: Anthropologie et sociologie, París: Quadrige/Presses Universitaires de France, 1950, p. 167. 
allí que Husserl pueda decir que "la actitud mítico-religiosa es interesada: tiene el fin de servir al hombre, para que pueda organizar su vida mundana, para que pueda preservarla de la enfermedad, de la miseria de la muerte" ${ }^{87}$. Interés, en latín, quiere decir "estar entre": el interés significa participar del juego, de la acción, de los intercambios simbólicos, de las prestaciones y las contraprestaciones, de dones y devoluciones, del acto de dar y recibir; interés significa que lo que ocurre en ese mundo es importante, que lo que allí pasa importa a los que están allí arraigados o sumergidos, que ellos están o son en ese mundo, que ellos se sumergen en ese mundo de transacciones y se dirigen hacia sus objetos, sus bienes y congéneres humanos con todas sus creencias, representaciones, valoraciones, juicios, dudas y prácticas sociales.

Pero, si seguimos las reflexiones de Husserl, ese mundo de la vida circundante en el que esa experiencia está inserta, que se les da a los campesinos dentro de un horizonte espacio-temporal, no abarca solo las cosas útiles o valores de uso, sino todas todos sus juicios, todos sus fines, todas las metas de su vida intencional, todas sus prácticas sociales o, en una palabra, las vivencias de todas sus tomas de posición sobre el mundo pre-dado ahí como existente. Ese "mundo está ahí" para ellos no solo como un mundo de cosas y objetos de uso, sino también como un "mundo de valores", "un mundo de bienes", un "mundo práctico" ${ }^{88}$. Eso quiere decir que estos intercambios simbólicos tampoco son reductibles al utilitarismo de la acción provechosa, interesada o meramente racional: ellos implican también valoraciones, disposiciones morales, puestas en sentido, constituciones de sentido que, en modo alguno, son reductibles al interés y la utilidad. Esos intercambios no son, por tanto, solo racionales, sino también razonables. Pero, al estar llenos de elementos religiosos, de mitos y de ritos, esos actos tienen también la propiedad de enmascarar la verdad objetiva de esos intercambios, el precio de esos intercambios, como si el precio debiera quedar implícito. Eso no quiere decir que los intercambios simbólicos o recíprocos no tengan un precio, sino que, aunque lo tengan, los campesinos deben actuar "como si" - por usar una expresión de Kant- esos intercambios no tuvieran precio alguno. Esa ambigüedad y esas verdades dobles de estos

87 Husserl, E., “La filosofía en la crisis de la humanidad europea”, en: Invitación a la fenomenología, Barcelona: Paidós, 1992, p. 102.

88 Cf. Husserl, E., Ideas relativas a una fenomenología pura y una filosofía fenomenológica. Libro primero: Introducción general a la filosofía pura, México D.F.: FCE, 2013, p. I37. En adelante, Ideas I. 
intercambios, que no son del todo desinteresados ni tampoco plenamente interesados, configuran las relaciones de reciprocidad entre los pastores de altura y sus deidades montañosas.

Ahora bien, con ocasión del cambio climático, los pastores de altura constatan que se han puesto en entredicho esas alianzas, esos intercambios recíprocos. Así nos lo hizo saber uno de nuestros interlocutores durante nuestro trabajo de campo:

[Felipe Cucho] (68 años): La lluvia no está cayendo en su debido tiempo, los truenos están matando personas, están matando animales. Además, la cantidad de lluvia ha disminuido. Los que creemos podemos afirmar que antes existían los “curacas (kurakakuna)". Ellos delegaban a una persona para que vigile los trabajos, él caminaba por todas partes, andaba con su poncho y no debía quitárselo. Si alguna vez se sacaba el poncho y un vecino veía, [este] decía: "Punchunta qalakuchkan kuraka, chayqa tiempuqa q'alaripunqataqchá" (Si el curaca se está quitando el poncho, entonces, pues, definitivamente el tiempo se revelará). Y, verdaderamente, el tiempo se ha descubierto: no hay lluvia. ¿Y qué vamos hacer? Es la laguna de Laramani, allá está Yanaqucha. Cuando no llueve, van a esas lagunas y traen el agua en botellas $y$, previo acuerdo, traen al cura, hacen misa al agua de las botellas y recién empieza a llover. Ahora es así. Antes el rayo no mataba a la gente ni a los animales porque en ese tiempo se pagaba a los cerros, a la lluvia y no había esos accidentes. Era raro. Estos últimos años, el 200I o 2002, pasaron accidentes de esa clase: ni siquiera en granizada, sino una noche de llovizna reventó el trueno y mató a una persona.

[Adhemir Flores]: ¿Y, entonces, qué fue lo que pasó?

[Felipe Cucho]: La gente se dio cuenta en todo el campo, hicieron su pago: "Manataq haywakunchikchu chay runata sipichkawanchik. Mejor, haywakusunchik" (Como no pagamos a la tierra, por eso se está matando a la gente. Mejor haremos nuestro pago). Y así, pagando y pagando, calmó. Eso hace pensar que siempre tenemos que hacer nuestros pagos. En esas cosas creemos. ${ }^{89}$

Tan pronto cuanto se deja de cumplir con la deuda de reciprocidad, las consecuencias para el mundo de la vida de los campesinos pueden ser tan perjudiciales como la muerte. Los pagos, las ofrendas, alejan las malas influencias y 
protegen a los seres humanos de las amenazas y las cosas siniestras. Por eso, dice Nietzsche que el sentido del culto es enrolar la naturaleza en beneficio del hombre y, por consiguiente, imprimirle un carácter de legalidad que no tiene de antemano, porque, echada a su suerte, ella aparece como el imperio de la libertad, como una suerte de poder arbitrario ${ }^{90}$. Si aplicamos esta lógica de la reciprocidad al cambio climático, este aparece como un signo de que hay una deuda de reciprocidad pendiente, como una señal de que hay una prestación unilateral de la divinidad local que espera una retribución por parte de los seres humanos. Como dice Sahlins, la reciprocidad es positiva cuando existe una relación simétrica o de equilibrio entre dar y recibir; y es negativa $o$ asimétrica cuando, por el contrario, las partes de los intercambios se limitan exclusivamente a dar o únicamente a recibir sin retribución alguna ${ }^{91}$. En su sentido positivo, la reciprocidad no solo implica no tener la libertad de negarse a recibir: supone la obligación de devolver. Por eso, Mauss insiste en que negarse a dar, olvidarse de invitar, así como negarse a recibir, significa declarar la guerra o contraer conflictos, significa rechazar la alianza y la comunión ${ }^{92}$. El cambio climático es una muestra de una alianza entre hombres y dioses que ha sido suspendida por la reciprocidad negativa y cuya restitución, en términos de reciprocidad positiva, es la que permite dotar de sentido el mundo, conjurar la violencia de las amenazas naturales y mantener un orden social más estable y duradero.

Tales creencias no necesitan ser fundadas, explicadas ni verificadas. Es más, en el contexto de enunciación aquí descrito, ni siquiera tiene sentido para los pastores de altura llamar a esto una "creencia" ni tampoco tienen necesidad de fundarla. Como dice el propio Husserl, una vez que estamos inmersos en todas estas vivencias cognitivas, axiológicas y prácticas propias, en esas puestas de sentido y tomas de posición desde las cuales comprendemos el mundo y nos comprendemos en él, no parecemos requerir tomar conciencia de los presupuestos de nuestra propia comprensión ${ }^{93}$. Del mismo modo, los pastores de altura, que están volcados hacia los objetos, las cosas y los otros sujetos de este mundo de un modo puramente práctico, no necesitan pregun-

90 Cf. Nietzsche, F., Humano, demasiado humano, Buenos Aires: EDAF, 2006, § III.

9l Cf. Sahlins, M., Economía de la edad de piedra, Madrid: Akal, 1983.

92 Mauss, M., op. cit., pp. I62-163.

93 Cf. Husserl, E., La idea de la fenomenología: cinco lecciones, México D.F.: FCE, 1982, p. 29. 
tarse por lo que sostiene todas esas creencias, todo ese edificio de creencias. En palabras de Wittgenstein: "lo difícil es percibir la falta de fundamento de nuestra creencia" ${ }^{44}$. En efecto, si queremos comprender esas constituciones de sentido, bastaría con describirlas, con "ver" y "mostrar" sus prácticas discursivas y sociales $y$, por medio de esas descripciones, dar cuenta del cómo de sus múltiples modos de constitución.

Sin embargo, conforme estas poblaciones pastoriles han ido estableciendo contactos o interacciones con creencias religiosas desde tiempos coloniales, sus constituciones de sentido también han sufrido profundas metamorfosis. En muchos casos, asistimos al desplazamiento o a la subordinación, en mayor - menor grado, de las creencias asociadas a los apus, a cambio de un lugar predominante para el paradigma interpretativo de las religiones protestantes. Estas transformaciones de sentido, estas adhesiones a nuevos sistemas de creencias, han sido constituidas o sedimentadas ya hace mucho tiempo, pero encuentran un terreno propicio para explicitarse con ocasión del cambio climático:

[Adhemir Flores]: En esta comunidad, iquiénes son los que sufren más con estas cosas?

[Nazario Cárdenas] (6I años): Todos por igual. Además, los más creyentes somos los que sufrimos más porque con la fe en Jesucristo debemos humillarnos como él, soportando enfermedades y desgracias, toda clase de dificultades, igual como Jesucristo. En ese entonces, fue humillado, y soportó los sufrimientos como un manso cordero hasta que fue crucificado. Así también Jesucristo nos dice: "iSíganme y cada cual cargue con su cruz!". Entonces, el que tiene más fe en Cristo, tiene que sufrir más desgracias y una serie de cosas. En fin, si cumples con la palabra de Dios sólo así llegas a ser un buen cristiano hijo de Dios y, cuando mueras, podrás llegar al reino de los cielos. Somos hombres mortales. Sólo Dios sabe si morimos hoy o mañana o al otro año: es su voluntad. Hoy en día, el comportamiento de las personas no es bueno: andan en cargos, fomentando fiestas, emborrachándose, creando pleitos, delinquiendo, matando, envidiando, robando, calumniando en la justicia, haciendo llorary sufrir a su prójimo, divorciándose. Así sucedió en el tiempo de Noé: la gente andaba sin fe en Dios desobedeciendo, haciendo culto a sus costumbres, adorando a la carne, haciendo su

Wittgenstein, L., Sobre la certeza, Barcelona: Gedisa, 1988, § 166. 
voluntad. Igual que hoy sucedía en el tiempo de Noé. En ese tiempo, sucedió el juicio del agua, donde llovió durante 40 días y 40 noches como si el agua se echara con un balde. Así llovía hasta que toda la tierra se cubrió de agua y se convirtió en mar, y sólo Noé navegó en las aguas porque él era obediente; navegó junto a su esposa, hijos e hijas; sólo ellos se salvaron y los animales que llevaron, hembra y macho, y la gente que se conducía mal, como, murió, todos murieron. Así dice el Señor Jesús: "Sucederá como en el tiempo de Noé para ustedes; ahora mi ira no será con agua sino con el fuego del sol. Será un juicio de fuego". Ahora, ya vemos que el agua se está secando, poco a poco, de año en año, disimuladamente; la lluvia está distinta; las heladas están raras, también el granizo: se dice que el granizo quemará a la gente. El sol calienta cada vez más fuerte. Todo eso ya está escrito ${ }^{95}$.

De ello se sigue que el cambio climático evoca no solo la suspensión del culto, la paralización del acto de reciprocidad con el cual se renueva la alianza con el Dios cristiano que, a diferencia de las deidades montañosas "ordenadoras" del mundo, aparece como el "creador" del universo. El cambio climático sugiere también que la economía del don no se está llevando a cabalidad en el comercio entre los seres humanos: alcoholismo, pleitos, crímenes, envidias, robos, calumnias y divorcios - precisa nuestro interlocutor-están imbricados profundamente con sequías, escasez de agua, incrementos de temperaturas, etc. La reciprocidad negativa, la ruptura de ciertos lazos sociales y el conflicto violento entre los seres humanos es el reverso de la reciprocidad violenta entre los eventos climáticos extremos y sus mundos de la vida. Si los seres humanos se niegan a rivalizar en generosidad mediante los intercambios recíprocos, no hay razones para que los hombres, los animales y la naturaleza sean buenos con ellos - piensan implícitamente los campesinos. Una vez que los miembros de esa comunidad humana particular se resisten a ser razonables mediante la práctica del don y la retribución, una vez que se rehúsan a asumir esos derechos y deberes simétricos de dar y recibir, una vez que se sustraen a consagrar ciertos lazos comunes, ciertas alianzas y contratos como miembros de una comunidad social compartida, se exponen tanto a las inclemencias del clima y los desastres de la naturaleza como a las amenazas constantes de la violencia y los conflictos sociales. No hay, pues, para los pastores de altura una separación entre naturaleza y sociedad o entre naturaleza y cultura: la naturaleza

95 Diálogo con campesino de la Comunidad de Sausaya Central, Canas, Cuzco. 
es naturaleza socializada y la sociedad está profundamente imbricada a la naturaleza. No hay allí ninguna relación de causalidad, sino una constelación compleja y recíproca: entre ambas existe una relación de continuidad por la que ellas se disuelven en una misma totalidad social de lo existente.

Es mediante estos intercambios simbólicos recíprocos que los pastores producen y reproducen múltiples modos de constitución de sentido. Esos intercambios, basados en prestaciones y contraprestaciones, en dones y devoluciones, en relaciones de reciprocidad y cooperación, constituyen el correlato de una experiencia intersubjetivamente comunizada de constitución de sentido y validez, de una vida intencional universalmente compartida por los pastores. No obstante, como señala nuestro interlocutor, son precisamente esos intercambios los que están siendo mermados por la falta de cooperación y el conflicto violento entre pares culturales. Los intercambios son "simbólicos" $-\sigma v v-\beta \alpha ́ \lambda \lambda \varepsilon \imath v$, "arrojar con", "poner con"- cuando ellos permiten "componer", "construir", "vincular" a unos seres humanos con otros, afianzar lazos sociales, lealtades y reciprocidades; por el contrario, son "diabólicos” -en el sentido pleno de la palabra- cuando "disgregan" y "descomponen" esa praxis intersubjetiva, esas relaciones sociales, mediante la larga lista de conductas sociales de reciprocidad negativa que describe arriba nuestro interlocutor. Cuando ocurre esto último, Dios desata su ira y conduce, como en los tiempos del diluvio universal, al despliegue arbitrario de las fuerzas naturales, poniendo en riesgo los mundos de la vida de los pastores. Eso produce una crisis de sentido, una crisis de las significaciones imaginarias sociales -valores, mitos, creencias, representaciones-que han servido de andamiaje a los pastores para organizar sus experiencias del mundo y constituir múltiples puestas de sentido del horizonte actual y potencial de sus mundos de la vida. Cuando hay una crisis de sentido, lo primero que se pone en tela de juicio es el lenguaje, ese conjunto de juegos de lenguaje con los cuales los seres humanos dotan de un sentido positivo a su existencia, organizan su forma de vida, crean y recrean sus instituciones y alejan la amenaza constante de la violencia.

No obstante, las épocas de crisis son también épocas de discernimiento, de creación de sentido, en un mundo que parece extraviarse en la tentación del sin-sentido. Como ha ocurrido en muchas sociedades antiguas, los campesinos encuentran en el sacrificio también una forma de restituir las alianzas, los intercambios recíprocos entre los hombres, y entre estos y la divinidad 
local, desplazando la violencia insatisfecha por cauces que no atenten contra la vida de los contratantes y los liberen, por tanto, de una violencia que amenaza las condiciones de reproducción de sus mundos de la vida. Como explica Girard con relación al sacrificio, "la sociedad intenta desviar hacia una víctima relativamente indiferente, una víctima 'sacrificable', una violencia que amenaza con herir a sus propios miembros, los que ella pretende proteger [a todo precio]"96. A los ojos de nuestro interlocutor, la peculiaridad de este sacrificio es que, de manera análoga a Cristo, el ser humano ha de sacrificarse a sí mismo, él tiene que humillarse y soportar las amenazas del clima, él ha de dirigir esa violencia insatisfecha hacia sí mismo, él tiene que asumir las consecuencias de su renuencia a consagrar la reciprocidad positiva y los intercambios simbólicos. Como recuerda Nietzsche, muchos pueblos que consagran el cristianismo necesitan un sacrificio para aplacar el profundo disgusto de Dios por el pecado y, desde entonces, no han dejado de descargar su descontento consigo mismos en una víctima ${ }^{97}$. Ese hecho es irreductible: doquiera que el cambio climático atenta contra determinadas formas de vida, siempre encuentra una víctima de recambio.

Esta crisis de sentido no es, sin embargo, para nuestro interlocutor, un acontecimiento inédito: "todo eso ya está escrito". Los eventos climáticos extremos y su agudización debido al cambio climático ya estaban pre-escritos o pre-anunciados en alguna cábala religiosa, en los mitos de origen o en los textos sagrados. Esa convicción coincide con la creencia, no menos extendida, de que dichos acontecimientos representan una muestra de una violencia a escala planetaria que provoca aquello que ya los textos apocalípticos anunciaban y revela una verdad pronunciada hace dos mil años atrás ${ }^{98}$. El cambio climático no refiere a un proceso de incertidumbre, sino a un proceso en el que reaparecen viejas certidumbres que adoptan el carácter de un discurso apocalíptico sobre este riesgo global:

[Adhemir Flores] [A.F.]: ¿Desde hace cuánto tiempo tienes fe en Dios? [Nazario Cárdenas] [N.]: Desde muy joven, yo tengo fe en nuestro Dios, más o menos desde 15 o 20 años. Yo ignoraba sobre los mandamientos

96 Girard, R., Le violence et le sacré, París: Gallimard, 1993, p. 13.

97 Cf. Nietzsche, F., Aurora: reflexiones sobre los prejuicios morales, Barcelona: Alba, 1999, § 94.

98 Cf. Girard, R., Clausewitz en los extremos: política, guerra y apocalipsis, Buenos Aires: Katz, 2010, p. II. 
y las órdenes de la ley de Dios porque en ellas Dios prohíbe las malas costumbres como el emborracharse (machay), fornicar (wich'uq), adulterar (wasanchanakuy), robar (suway), mentir (Ilullakuy), ser ambicioso, las envidias hacia nuestro prójimo. Todo esto prohíbe. Dios no quiere que hagas lo que exige la carne, sino que estés lleno del Espíritu Santo y ser una persona fiel, obediente, misericordiosa, dadivosa, hospitalaria, enseñarle al que no sabe. Día y noche debemos vivir clamando a Dios, agradeciéndole día y noche, por la mañana y por la tarde, dándole gracias por las bendiciones que nos da. No debemos vivir callados como los animales esperando comer, ir a la chacra, comer y dormir, yendo tras el dinero sin tener en cuenta la palabra de Dios.

[A.F.]: Ah ya, entiendo. Ahora bien, hace un momento me dijiste que las personas de este tiempo no obedecen. ¿Es eso lo que se dice por aquí? [N.]: Eso dicen. Como el sol está quemando demasiado; por eso, son las heladas, las granizadas, el frío.

[A.F.]: ¿Y los abuelos qué dicen?

[N.]: Dicen que antiguamente no era así: ni el sol, ni el frío, ni la helada [eran así]. Los abuelos, como en mi caso, seguro dicen que es por la desobediencia del hombre a los mandamientos de Dios. Porque Dios lo quiere así.

[A.F.]: ¿Ese es tu pensamiento, entonces?

[N.]: No sólo es mi pensamiento, sino es la santa sagrada Biblia la que lo dice: "Para aquel que cumple mi palabra sus obras serán bendecidas, su trabajoy su alimento será abundante, hasta sus animales se reproducirán en abundancia. Para él, no habrá enfermedades, no habrá llantos ni tristezas, no tendrá pobrezas. Mientras más estén conmigo florecerán en alegrías y gozo". Así dice. Ahora, "para aquel que no obedece, esto acontecerá: el viento arrasará con su casa, las lluvias y los derrumbes afectarán sus moradas, aparecerán toda clase de enfermedades y no podrán sanar". Así habla Dios: nos habla mediante las escrituras de la Santa Biblia. Como un testamento que ha dejado ahí está la ley de Dios ${ }^{99}$.

Como señala Nazario Cárdenas, el hombre ha sido apartado de la unión del culto con la divinidad y ha quedado abandonado a sí mismo. El mundo ya no ofrece un cobijo y una forma de inmunidad frente al "silencio eterno de esos espacios infinitos", como diría Pascal, y se ha convertido, por usar una expresión de Nietzsche, en "un portón a mil desiertos, vacíos y fríos". Desamparado y expuesto ante los acontecimientos de la naturaleza y las necesidades de la vida y la muerte, aparece una nueva interpretación de la divinidad como 
entidad "creadora" del mundo y "auxiliadora" para la vida humana, en la cual los hombres -a menudo impotentes- encuentran su mayor refugio frente al cambio climático. Es el dios de la causalidad, el "dios creador del orden natural", un dios humano, demasiado humano, cuya presencia no es sino una "idea abstracta" omnipotente: un dios que lo ha creado todo y que lo puede todo, que ha creado el clima y que puede controlarlo todo ${ }^{100}$. De esta forma, los principales afectados experimentan la sensación de poder engrandecer una condición humana que, de otro modo, podría parecer pequeña e impotente frente al cambio climático.

Sin embargo, decir que el cambio climático es una prueba más de una predicción milenaria podría ser una forma de reduccionismo para quienes comparten una experiencia religiosa. Si bien las alteraciones en el orden natural aparecen ligadas al cambio climático, hechos históricos como este no pueden servir de prueba para las creencias religiosas de los pastores de altura. Los campesinos de alta montaña pueden, incluso, ofrecer pruebas, pero estas igualmente serían insuficientes para desvelar las posibilidades de sentido de una experiencia que está más allá de toda prueba. Husserl reconoce que el mundo no puede ser inteligible sin la lógica, sin ese esfuerzo de puesta en sentido, pero el mundo y la totalidad de lo existente -lo sabemos- no es reductible a la mera lógica. De allí que temas como la historia, la muerte, el destino y los problemas ético-religiosos sean, para Husserl, procesos fortuitos que descansan en una irracionalidad previa, en un trasfondo inconsciente que subyace a la vida de la razón. En ese sentido, la gente no tiene que probar nada, porque ese paradigma interpretativo descansa en un pensamiento completamente diferente. Esa experiencia se sitúa en un plano distinto; en él, no se puede aplicar la duda que se aplica, por ejemplo, a cualquier hecho histórico. Todos los términos religiosos parecen ser solo símiles o analogías de algo; tan pronto cuanto se refieren a hechos, no son más que sinsentidos porque, cuando dejamos los símiles para enunciar o describir los hechos, descubrimos que no hay tales hechos $^{101}$. La experiencia religiosa no reside sino en el milagro, y no hay mayor milagro -dice Wittgenstein- que el lenguaje mismo ${ }^{102}$. Es el lenguaje

100 Cf. Sloterdijk, P., Crítica de la razón cínica, Madrid: Siruela, 2004, pp. 69-72.

I0I Cf. Wittgenstein, L., "Lecciones sobre la creencia religiosa”, en: Lecciones y conversaciones sobre estética, psicología y creencia religiosa, Barcelona: Paidós, 1992, p. 134.

102 Cf. Wittgenstein, L. Conferencia sobre ética, Barcelona: Paidós, 1990, p. 42. 
un acontecimiento milagroso en contraposición con la violencia ciega y sin fin que hace retroceder la reciprocidad y los intercambios simbólicos. Es el lenguaje propio de la experiencia religiosa el que se contrapone a la violencia organizada que está en la base de la crisis ecológica y el cambio climático. Todo lo que digamos del lenguaje religioso es, por ello, limitadamente accesible, porque, como muestra la fenomenología trascendental, toda constitución de ese sentido siempre contiene un horizonte potencial -no solo actual-donde queda co-expresada o co-mentada la remisión a otras experiencias posibles ${ }^{103}$.

Ahora bien, hay pastores -especialmente los más jóvenes- que, sin claudicar necesariamente ante los discursos religiosos precedentes, buscan "explicaciones" sobre las condiciones actuales del clima, usando ciertos elementos de un paradigma interpretativo diferente. Estos jóvenes, que han tenido la experiencia de la educación oficial, que vivieron la experiencia de la migración y que interactúan con ese proceso de mayor interdependencia mundial que llamamos globalización, tienen una lectura que entronca más con un sentido universalmente compartido sobre el cambio climático:

[Adhemir Flores]: Me gustaría que me cuente qué problemas están enfrentando actualmente con el clima y por qué está ocurriendo eso. [Ramón Mamani] (38 años): Puede ser por el cambio de clima causado por la contaminación. Como cerca tenemos a la Mina Tintaya; luego, el crecimiento de las ciudades y la contaminación de los ríos. Creo que esos son los factores que contribuyen al cambio de clima, como el deterioro de la capa de ozono. Entonces, es causa para que el sol caliente con fuerza. Creo que la contaminación es lo que malogra, la contaminación de los carros, de las fábricas, la quema de productos tóxicos. Con esto, el tiempo está cambiando poco a poco, ya no es como antes. Antes, la papa producía así de grandes como la variedad "qachalli". Ahora ya desparecieron las papas nativas que servían para la elaboración de moraya y chuño... Luego, también en la Biblia hemos leído y ahí está escrito que estos acontecimientos de clima pasarán para el regreso de Dios, y se está cumpliendo, el agua está escaseando tal como dice la Biblia... Ahí, en la Biblia, dice que Jesucristo regresará, cuando el sol caliente más, el agua se extinga, cuando haya hambruna. Así será el fin del mundo. Eso está escrito en la Biblia. Además de los cambios climáticos, vemos que hay mucha corrupción, demasiadas 
enemistades por la tenencia de las tierras y eso lo dice la Biblia y está sucediendo... Porque en esta tierra los grandes científicos no creen en Dios, ya que ellos realizan experimentos, logran producir plantas híbridas, realizan experimentos en otros planetas, llevan productos para sembrar. Definitivamente, ellos ya no creen en Dios, creen en ellos y hasta se creen dioses $y$, cuando llegue el fin del mundo, ellos viajarán a otros planetas. Pero, los países pobres se quedarán, se secarán las aguas; y eso está escrito en la Biblia y se cumple. Como vemos, hay gente de toda condición, hay de todo. Como voy a visitar a mis familiares a diferentes pueblos que voy a trabajar, observo una serie de cosas como la prostitución. A eso Dios envía como un castigo. ${ }^{104}$

Aquí vemos dos constituciones de sentido diferentes que coexisten en conflicto. En un primer momento, la naturaleza aparece, desde la significación imaginaria de la tecno-ciencia, como un mecanismo gobernado por causas y leyes autónomas que ha sufrido serias trasformaciones por obra de la intervención humana; en un segundo momento, el discurso religioso aparece en una posición subalterna o subordinada, pero poniendo a prueba el discurso moral del primero.

En un lado del espectro, la nueva significación imaginaria dominante asume que la naturaleza es un gran mecanismo autónomo que es vulnerado con la misma fuerza con que pretende ser dominado por la producción tecno-científica moderna que la pone a su servicio. Con Galileo comienza la sustitución de la naturaleza pre-científica por la concepción fisicalista de un mundo escrito en lenguaje matemático o, vale decir, la clausura de la significación del mundo, al excluir u oscurecer otras constituciones de sentido posibles. Pero, el problema -precisa Husserl- no es solo que esta interpretación de la naturaleza se aleje de la fuente de intuición y constitución originaria que es el mundo de la vida, sino que "el mundo de las idealidades matemáticas" se asuma como "el mundo dado efectiva y perceptivamente", "el experienciado y el experienciable", "nuestro mundo de la vida cotidiano"105. Esta significación social imaginaria ha servido para aprovechar posteriormente las posibilidades biofísicas de una naturaleza devenida "medio ambiente". Si un significado profundo tiene

104 Diálogo con campesino de comunidad de Sausaya Central, Canas, Cuzco.

105 Husserl, E., La crisis de las ciencias europeas y la fenomenología trascendental, Buenos Aires: Prometeo, 2008, p. 92. 
la palabra "ambiente", es precisamente que nunca antes la naturaleza y las condiciones de vida de las poblaciones que dependen inmediatamente de ella habían sido tan alteradas por la acción humana. En el mundo moderno, el trabajo no solo es, a la vez, espacio de realización y sujeción del ser humano, sino también lucha constante con la naturaleza para dominarla y sacar provecho de ella. Bacon y Descartes habían compartido, como consigna espiritual moderna, la idea de ser "amos y dueños de la naturaleza"; pero ninguno de los dos hubiera imaginado y aceptado como razonable no solo que un dominio absoluto fuera posible, sino que se lleve a cabo por el mero lucro y el sustento, al margen de toda finalidad moral que el primero encontraba en la caridad ${ }^{106}$ y el segundo, en la responsabilidad de una colectividad autónoma y libre. Lo cierto es que, contra toda sospecha, esta antropología filosófica del homo faber, que reduce al ser humano a "animal productor" -productor de mercancías, de conocimientos, de valores, de instituciones, de otros seres vivos- y que el capitalismo ha llevado a su máxima realización, ha dado lugar al programa moderno del dominio ilimitado de la naturaleza, poniendo en tela de juicio toda forma de vida en general y, con ella, la vida humana ${ }^{107}$. Aquí ya no se trata de reciprocidad positiva con la naturaleza socializada y sacralizada, sino de una reciprocidad negativa que adquiere la determinación de una relación impersonal, económica y abstracta con los -ahora llamadosrecursos naturales, que han encontrado, en el discurso de la tecno-ciencia y en las políticas extractivistas o desarrollistas que hoy hacen época, una praxis aparentemente autorizada. En los últimos siglos, la consecuencia imprevisible de las desmesuradas proporciones de esta civilización tecno-científica ha sido, sin embargo, la degradación ecológica, la contaminación ambiental y el cambio climático.

Los campesinos optan por adherirse, en algún grado, a esta significación imaginaria para no sucumbir al riesgo del "vacío de sentido" que entraña el cambio climático. Conforme estas poblaciones de alta montaña han ido interactuando, a lo largo de la historia, con otras formas de vida, con nuevos mercados, con nuevos sistemas de comunicación, con nuevas esferas de integración social, ellas han experimentado ciertas rupturas con sus identidades sociales y con

106 Cf. Bacon, F., El avance del saber, Madrid: Alianza Editorial, 1988, pp. 2I-22ss.

107 Cf. Jonas, H., The Imperative of Responsibility: In Search on an Ethics for the Technological Age, Chicago/Londres: Chicago University Press, 1984. 
esos sistemas de inmunidad proporcionados por las creencias, las normas, los valores, las referencias de sentido y las motivaciones que sus propias instituciones encarnan. El cambio climático aparece como un riesgo fabricado por la acción humana, que hace violencia al mundo de certidumbres de los campesinos y su mundo de la vida en general al suspender las relaciones de reciprocidad entre naturaleza y sociedad y entre diferentes grupos de la sociedad mundial. No se trata de la supresión del mundo, ya que este permanece intacto en su propia existencia, sino de la supresión del mundo de las daciones actuales, las aprehensiones, las matizaciones ${ }^{108} \mathrm{y}$, en un sentido más amplio, de la puesta en cuestión del mundo de certidumbres, creencias y representaciones de los campesinos, desde el punto de vista de la adecuación de sus puestas en sentido o vivencias previas con el estado de cosas actual. Los campesinos encuentran, entonces, en la significación imaginaria de la tecno-ciencia una posibilidad de sentido en medio de un estado de cosas marcado por el sin-sentido, por la experiencia del absurdo o, como dice Husserl en otro contexto, por la "experiencia del conflicto" entre sus intenciones y su cuasi-cumplimiento, por la experiencia del "ideal negativo de la frustración última”109.

En el otro lado del espectro, si bien la versión periférica o reducida de este paradigma de corte tecno-científico es ya parte de las significaciones imaginarias de las poblaciones campesinas, no elimina, sin embargo, el paradigma religioso que subyace, de manera latente o abierta, dentro del horizonte de posibilidades de sentido de los pastores de alta montaña. Antes bien, este paradigma tecno-científico surge, aquí, para revestir, ocultar o eclipsar ese sentido históricamente sedimentado, previamente constituido, que los pastores también consagran. La persistencia de sus creencias religiosas muestra que los resultados del paradigma tecno-científico no satisfacen a los campesinos, que el cambio climático plantea cuestiones que escapan a las preguntas por el conocimiento de los meros hechos del mundo. Es allí donde para Kant surge la posibilidad de los fines últimos de la razón: la moral comienza allí donde acaba el conocimiento y emerge la pregunta por la libertad y la responsabilidad. Esta cuestión, que concierne a la humanidad, aparece sugerida en tres preguntas fundamentales que Kant formuló: “¿Qué puedo conocer?”, “iqué debo hacer?”,

108 Cf. Ideas I, § 49, pp. I87-188.

109 Husserl, E., Logical Investigations. Volume Two, Londres/Nueva Jersey: Routledge \& Kegan Paul/Humanities Press, 1970, VI, § 39, p. 769. 
“iqué puedo esperar?". La dignidad de estas preguntas es que sobrepasan las preguntas por los "meros hechos", van más allá de todo conocimiento tecnocientífico posible. Todas ellas se reúnen en una pregunta ética radical que Kant, a diferencia de sus predecesores, por primera vez explicitó: "¿Qué es el ser humano?". Como ocurre con otros problemas y riesgos globales, con el cambio climático el ser humano deviene, entonces, un problema filosófico por excelencia, porque lo que está aquí en cuestión es el ser humano como ser razonable, y si se cuestiona su historia, se trata del sentido, de lo razonable en la historia. Los pastores de camélidos sudamericanos parecen haber comprendido el trasfondo de esa cuestión cuando recurren, con cierta ironía moral, al ejemplo del cambio climático para interpelar la tentación de omnipotencia del discurso tecno-científico y dar a conocer su sentido de justicia, al ser ellos los principales afectados por el cambio climático. Reiteremos, una vez más, las palabras de nuestro interlocutor: “(...) en esta tierra los grandes científicos no creen en Dios, ya que ellos realizan experimentos, logran producir plantas híbridas, realizan experimentos en otros planetas, llevan productos para sembrar. Definitivamente, ellos ya no creen en Dios, creen en ellos y hasta se creen dioses $y$, cuando llegue el fin del mundo, ellos viajarán a otros planetas. Pero, los países pobres se quedarán, se secarán las aguas, y eso está escrito en la biblia y se cumple". En efecto, una sociedad que sobrevalora dogmáticamente el conocimiento tecno-científico y que es fruto del arbitrio y de los intereses concentrados en las preocupaciones económicas privadas-sin menoscabo de las miserias que pueden ser mayores que la abundancia-, $y$ un Estado que es racional y extractivo y que actúa únicamente movido por el unilateralismo de sus intereses, decidido a ampliar sus dominios y ganar territorios y recursos naturales, contrastan, sin duda, con la definida y razonable naturaleza moral de estos pueblos, que no son agresivos con otros, que defienden su territorio como si de todo eso dependiera todo su mundo de la vida y que buscan afianzar la "seguridad ontológica" de sus miembros para seguir dotando de un sentido positivo a su existencia. La tragedia de estos pueblos es, entonces, la que padecen cuando su vida ética razonable se enfrenta a un Estado o una sociedad mundial que no puede compensar, con toda su grandeza material, el riesgo de hacerse amoral a fuerza de hacerse racional.

Esta tensión entre diferentes significaciones imaginarias se oscurece tan pronto cuanto ambos paradigmas aparecen en una misma trama discursiva -como en el testimonio arriba descrito. Allí se pierde de vista el hecho irreductible 
de que ambos paradigmas interpretativos se sitúan en planos de vivencias y constitución de validez completamente diferentes: el discurso tecnocientista aparece como relato dominante, mientras que el religioso aparece como una premisa que sirve para corroborar un discurso legitimado de antemano. Eso puede prestarse a lecturas tendenciosas que no están exentas de ejemplos históricos. El antropólogo Frazer llevó a su extremo esa pretensión cuando se acercó a las creencias de sus interlocutores asumiendo que ellas representaban no una "visión distinta", sino una mera doxa frente a una episteme o, mejor aun, una suerte de mentalidad pre-lógica, una pseudo-ciencia, una ciencia falsa en la medida que las creencias en que se asientan no corresponden con el juego de lenguaje de la verificación y la eficacia experimental ${ }^{110}$. Con ello -podría haber dicho Husserl-, Frazer confundió los criterios de verdad que valen para una doxa epistémica con los que valen para una toma de posición axiológica o práctica: “(...) pedir la perfección que pertenece a la evidencia en una esfera (por ejemplo, el de las relaciones esenciales) en otras esferas que la excluyen esencialmente, es un contrasentido"|II. Una situación similar ocurre cuando el discurso global sobre glaciares en extinción ignora puntos de vista alternativos sobre el cambio climático, al asumir que esos relatos -y las personas locales que los sostienen-son irracionales ${ }^{12}$. Como precisa Bourdieu, el mundo social es, por ello, lo más difícil de conocer porque embruja los cerebros que se dedican a analizarlos y oculta, bajo las apariencias más triviales, las revelaciones más inesperadas con respecto a lo que queremos saber, al menos, sobre lo que nosotros somos y -podemos agregar- sobre lo que los otros son ${ }^{113}$.

Así, pues, la posibilidad de que los jóvenes pastores se hayan podido apropiar de todas las constituciones de sentido descritas anteriormente es, sin duda, un resultado de sus propias experiencias del mundo. Pero la fenomenología muestra que estas constituciones de sentido, múltiples y dinámicas, no pudieron ser posibles sin esa historia de sentido que se ha ido sedimentando desde un trasfondo previo de síntesis pasivas de sentido, desde una prehistoria de sentido inscrita en la vida pre-egológica, inconsciente, que, luego, alcanza su

II0 Cf. Wittgenstein. L., Observaciones a La rama dorada de Frazer, Madrid: Tecnos, 200 I.

III Ideas I, § I38, p. 423.

II2 Cf. Carey, M., "The History of Ice: How Glaciers Became an Endangered Species", en: Environmental History, XII (2007), p. 519.

II3 Cf. Bourdieu, P., Méditations pascaliennes, París: Éditions du Seuils, 2003, pp. 19-20. 
máxima expresión en el lenguaje, en esos juegos de lenguaje que conciernen a la vida de los campesinos frente al cambio climático. En efecto, las cosas se nos dan no solo por las vivencias inconscientes y la percepción o la intuición originaria: se nos dan con su sentido objetivo ya constituido ${ }^{114}$. La intuición pre-lingüística y el lenguaje son los maestros con los cuales los campesinos han aprendido la reciprocidad y sus intercambios simbólicos con los dioses y con otros seres humanos, así como los idiomas de creencias asociados a la contaminación ambiental y el cambio climático reciente. Es gracias al lenguaje que estos términos adquieren sentido para los pastores, y ellos conjugan estas diferentes significaciones imaginarias en sus diferentes situaciones de referencia con ocasión de la crisis de sentido que impone el cambio climático. Los pastores comprenden el mundo y se comprenden gracias a las sedimentaciones y posibilidades de sentido que ofrecen estos múltiples modos de constitución a lo largo de su historia personal y su herencia histórico-social. Eso significa que, para la fenomenología, "el sentido es fluido", del mismo modo que lo son las corrientes de vivencias de los principales afectados por el cambio climático.

\section{\$ 2. Una responsabilidad ética frente al cambio climático basada en la intersubjetividad comunicativa de toda constitución de sentido}

La fenomenología invita a los científicos y a la sociedad política a tomar distancia crítica de sus propias constituciones de sentido y a reconocer que la fuente última de toda constitución de sentido sobre el cambio climático es el "mundo de la vida". Desde la perspectiva fenomenológica, el mundo de la vida es el "horizonte" de cosas y objetos que participan de la forma espacio-temporal abierta de nuestra vida intencional. Cada ser humano puede comprender su cultura y sus horizontes aún no descubiertos precisamente en tanto miembro de la sociedad que lo ha formado históricamente, en razón de las estructuras sociales que ha internalizado en los habitus o disposiciones permanentes que caracterizan a su yo personal. Pero, dado que la apresentación permite efectuar una repetición potencialmente infinita de menciones y verificaciones, de convicciones y valoraciones, los agentes pueden abrir nuevas posibilidades 
interpretativas del sentido del pasado y orientarse con "habitus diferentes" hacia nuevas posibilidades de sentido en el futuro, las cuales les permitirán una comprensión ampliada del presente. Así, las constituciones de sentido sobre el cambio climático no pueden ser reductibles a meras constituciones dóxicas o epistémicas: exigen, sobre todo, nuevas constituciones éticas y prácticas. Así, la fenomenología invita a reconocer que ninguna constitución de sentido actual sobre el cambio climático es la única posible y que ninguna constitución de sentido particular (epistémica, política o cultural) agota otras puestas en sentido posibles. Cada sentido es, entonces, un excedente de otras remisiones de sentido posibles que se extienden hacia el infinito; hay, en efecto, un sentido actual y otro posible, un sentido presente y otro ausente. Admitir esto significa liberar a toda posición dóxica, axiológica y práctica de cualquier tentación dogmática y reconocerle sus límites ante el tribunal de la razón. En una palabra, hacer eso significa conducir a toda posición epistémica, axiológica y práctica a la crítica constante como condición de posibilidad para la adopción de una ineludible ética de la responsabilidad frente al cambio climático.

Sin embargo, ese tribunal de la razón remite a una intersubjetividad comunicativa de constitución. Husserl insiste en que toda constitución de sentido y validez solo es posible dentro del horizonte de una experiencia intersubjetiva ${ }^{115}$. Toda constitución de sentido no es algo que trascienda la intersubjetividad, sino que esta le es inmanente: el mundo y todo estado de cosas está siempre referido a una experiencia intersubjetivamente comunizada de pretensiones de sentido y validez, a una vida intencional universalmente compartida ${ }^{16}$. Por esas razones, la acreditación de toda puesta de sentido, la evidencia perfecta, la auténtica verdad sobre el cambio climático solo puede ser un "ideal regulativo", una "idea-guía”, idea directriz", que destaca por una infinitud que está implícitamente actuando en el flujo continuo de cada nueva síntesis concordante, en el nexo concordante consciente de cada puesta de sentido constituida intersubjetivamente entre científicos, Estados y ciudadanos organizados. De allí que se pueda decir después que la verdad y validez de las evidencias sobre el cambio climático dependen menos de la mera objetividad de nuestros juicios, de la simple correspondencia entre nuestras percepciones y las cosas,

115 Cf. Ideas I, § I35, p. 410.

II6 Cf. Husserl, E., Méditations cartésiennes: introduction à la phénoménologie, París: J. Vrin, 1969, § 50. 
que de la discusión crítica, de la problematización y del consenso alcanzado por las personas sobre la realidad o el estado de cosas. Toda constitución de sentido, toda puesta en sentido frente a la crisis ecológica no es, pues, una verdad intersubjetivamente acabada, perfectamente adecuada, sino continua, gradual y abierta.

Esto entraña, en efecto, consecuencias políticas irreductibles. La democracia es, como dice Castoriadis, la posibilidad de que una colectividad pueda reconocerse como la fuente de la institución imaginaria de la sociedad, de que sus miembros puedan reconocerse, examinar y darse, de manera crítica, lúcida y explícita, sus propios fines, sus valores, sus leyes, sus instituciones ${ }^{117}$. La democracia es, por tanto, el régimen de la autonomía y la responsabilidad política. Una sociedad o una persona autónoma es aquella que es capaz de reconocer que la fuente de toda constitución de sentido es la sociedad misma, es decir, que hacemos o creamos nuestros bienes, fines y valores, tradiciones, leyes e instituciones y que, por tanto, podemos revisarlas, cuestionarlas y modificarlas continuamente mediante la discusión crítica y la acción colectiva. De ello resulta la apertura a la posibilidad de interrogar las creencias y las instituciones existentes, que ya no son sagradas, trascendentes, intocables o indiscutibles en una sociedad autónoma y democrática ${ }^{118}$. Todo proceso democrático forma o educa ciudadanas y ciudadanos autónomos, y estos, a su vez, son condición de posibilidad para la institucionalización y la revisión crítica constante de sus puestas de sentido, de sus fines, sus valores y sus prácticas sociales, pues, como cualquier ideal regulativo que escapa a todo conocimiento científico y a toda certeza última, la democracia es un proceso por hacerse y re-hacerse. De ello se sigue que, en un contexto mundial marcado por la crisis ecológica y el cambio climático, todos deben poder participar realmente (no solo formalmente) de esa crítica de los bienes, de los fines, de las leyes y de las instituciones; todos deben poder querer participar de esos intercambios simbólicos, de esas donaciones y contraprestaciones, de esos procesos por los cuales damos y recibimos razones en el diálogo y la discusión crítica. En efecto, respetar la dignidad humana es respetar sus intercambios simbólicos, es permitirles a todos ser parte, participar, de esos intercambios recíprocos, del proceso por el cual damos y recibimos fines, de esa

II7 Cf. Castoriadis, C., "¿Qué democracia?", en: Figuras de lo pensable, Madrid: Cátedra, 1999, pp. I42-176.

II8 Cf. Castoriadis, C., El avance de la insignificancia, Buenos Aires: Eudeba, 1997, pp. 197-199. 
actividad crítica de los bienes y los valores sobre los cuales pende la democracia. Solo así el cambio climático podrá estar guiado por principios de justicia.

Así, pues, la filosofía -y la fenomenología, en particular- es esencialmente la pregunta por el sentido, por las constituciones de sentido, por la historia del sentido -sentido que es impensable fuera de la historia de sentido de una colectividad, porque es la sociedad la que constituye sentido a partir de sentidos ya constituidos. La crisis de sentido que impone el cambio climático es un problema, pero también una oportunidad para otorgarle nuevamente dignidad a la pregunta por el sentido del orden social existente a escala local y universal. Eso quiere decir que el "tribunal de la razón" es, para Husserl, la colectividad humana, y esta es la última instancia competente para la descripción de las relaciones entre razón y realidad, pues todas las descripciones entran en el terreno de esa razón, de lo que la humanidad puede interrogar, decidir y sancionar por intermedio de ella de manera crítica y auto-reflexiva. En ese contexto, la filosofía debe responder racionalmente por las significaciones imaginarias de su época, debe hacerse cargo de las fuentes de sentido y validez últimas de la sociedad, reconociendo que ese ejercicio no se reduce a la actividad teorética, sino que también se extiende a toda vida

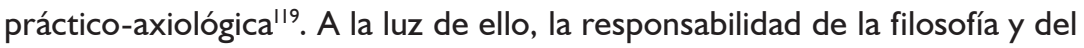
filósofo consiste en dar cuenta de aquello que hay de sensato o razonable en el mundo de la vida y la condición humana en un sentido universal, porque, en buena cuenta, la filosofía ha construido históricamente el "concepto de razón”, es decir, su marcha está íntimamente ligada al “destino de la razón”"20. Y, sin embargo, Husserl reconoce que es tarea del filósofo justificar la vida, aunque ella no esté precisamente guiada por la razón, aunque la humanidad no siga precisamente el curso de la marcha de la razón, de la "humanización del hombre"|2|. De hecho, el cambio climático es, para los pastores de alta montaña, un acontecimiento que ha puesto en tela de juicio la posibilidad de llevar una vida razonable y sensata a nivel global y local. El hecho paradójico de que la filosofía no puede renunciar a lo razonable, aunque pocas cosas en

II9 Cf. Husserl, E., Philosophie première 2: théorie de la réduction phénoménologique, París: Presses Universitaires de France, 1972, pp. 3-4.

I20 Cf. Ladrière, J., "Responsabilité de la philosophie", en: Le temps du possible, Lovaina: L'Institut Supérieur de Philosophie Louvain-La-Neuve/Peeters, 2004, pp. 7-16.

I2I Cf. Husserl, E., "La filosofía como autorreflexión de la humanidad", en: Invitación a la fenomenología, Barcelona: Paidós, 1992, p. 135, nota I. 
el mundo, como el cambio climático, estén motivadas por el hecho de ser razonables, es probablemente uno de los más grandes retos de toda filosofía posible. Una fenomenología social del cambio climático implica, por tanto, la tarea infinita de excavar en el sentido fluido de toda constitución intersubjetiva pasada, actual y posible.

\section{§ 3. Algunas conclusiones}

De las consideraciones anteriores se desprende que la crisis de sentido con ocasión del cambio climático es también de la historia del sentido, de las múltiples constituciones de sentido que forman parte de las significaciones sociales imaginarias con las cuales los pastores de las comunidades de alta montaña interpretan las condiciones históricas y actuales de sus mundos de la vida. La violencia que impone el cambio climático está hecha de la misma tela que la violencia ciega y sin fin con la que los seres humanos renuncian a la reciprocidad positiva y los intercambios simbólicos, a cambio de establecer una brecha -inimaginable para las sociedades pastoriles- entre naturaleza y sociedad, en la que las partes del intercambio únicamente se limitan a dar y a recibir sin retribución simétrica. En ese contexto, hemos visto cómo los campesinos crean y recrean sus significaciones imaginarias, sus constituciones de sentido, en medio de la crisis de sentido que les impone el cambio climático: ellos no renuncian a un sentido posible en medio de la amenaza de todo sentido en el orden social existente; pero cuestionan la totalidad de lo existente, sin necesidad de requerir fundamentar sus creencias ni los presupuestos de toda constitución; antes bien, ellos hacen todo para ocultarlo, y lo hacen imputando a una fuente extra-social religiosa o científica el fundamento o la justificación de sus diferentes modos de constitución. El cambio climático pone en tela de juicio sus mundos de certidumbres, pero ellos también encuentran en él una ocasión para interrogarse y responder a esas interrogantes desde diferentes paradigmas interpretativos.

El reconocimiento de que no existe una sino múltiples constituciones de sentido, relativiza y desarma cualquier tentación cientificista y dogmática de llevar la delantera en materia de cambio climático, así como cualquier tentativa política de adoptar acciones al margen de la voz y el asentimiento de los principales afectados. Pues, si se procediese de esta manera, el discurso científico sería 
incapaz de reconocer que sus constituciones de sentido son solo un juego de lenguaje entre otros posibles, y podría ocultar el hecho de que los campesinos tienen también sus idiomas de creencias, sus propias valoraciones y sus propias pretensiones de validez, aun cuando se cuestionen sus perspectivas de riesgos conocidas con la misma fuerza con que el cambio climático y sus peligros hacen estallar sus constituciones de sentido previas. Adicionalmente, al pretender tomar decisiones sobre las acciones que deberían adoptarse al margen del asentimiento de los principales afectados, la acción política podría ser incapaz de reconocer a los campesinos o indígenas como ciudadanos e interlocutores legítimos en los procedimientos de discusión y deliberación pública. El riesgo podría ser que los remedios que la sociedad mayor propone frente a los problemas que enfrentan las poblaciones más afectadas podrían ser peores que la supuesta enfermedad que acompaña a toda época de crisis. De ser así, el cambio climático plantearía un problema de justicia global más complejo, no solo porque resulta que las poblaciones más afectadas son las que menos han contribuido en él, sino porque su diferencia cultural y su forma de vida no serían plenamente reconocidas en las investigaciones ni en las acciones que se adoptan para afrontarlo. Eso socavaría las bases de todo proceso de democratización y entrañaría el riesgo de que la violencia impuesta por el cambio climático siempre encuentre alguna víctima de recambio, tanto entre las poblaciones del presente como entre las generaciones del futuro que no pueden decidir qué hacer ahora. La acción política puede recurrir a la ciencia para orientarse frente al cambio climático, pero la acción tiene una validez que no rige igualmente para cualquier doxa epistémica.

La pregunta por los fines últimos de la razón es la pregunta por otorgarle una finalidad moral a todo conocimiento y toda acción posibles. La crisis ecológica y el cambio climático hacen ineludible la pregunta por aquello que podemos conocer, que debemos hacery que podemos esperar. Con el cambio climático, retorna la vieja pregunta ética por excelencia de quiénes somos y quiénes queremos ser. Pero, la respuesta provisoria y parcial a esa cuestión solo es posible mediante un proceso de democratización que pueda ser capaz de incorporar a los marginados a esos procesos de toma decisión, mediante los cuales seres humanos establecen intercambios simbólicos, relaciones de reciprocidad y cooperación social que alejan la amenaza de la violencia, de la guerra civil, de los autoritarismos, etc. Por eso, decía Montaigne, no hace falta mucha ciencia para actuar como es debido. No puede haber recetas 
tecno-científicas ni de ningún tipo frente al cambio climático, porque allí donde acaba el conocimiento científico comienza la acción moral, la responsabilidad moral y política. La democratización no es el proceso del saber cierto y asegurado, sino el de los intercambios simbólicos y la reciprocidad. Al explicitar las condiciones históricas de posibilidad que están en la base de las prácticas discursivas de los campesinos, de los científicos y de la sociedad política, la fenomenología puede ayudar a disipar las ilusiones de las puestas de sentido actuales y hacer un llamado a tomar esta crisis de sentido como una oportunidad para que la humanidad pueda examinar sus puestas de sentido de manera autónoma y desde una perspectiva de la responsabilidad universal. Las épocas de crisis (chrinein, "discernir") son también, por ello, épocas de discernimiento, de actividad crítica, de cierta dosis de escepticismo, pero también de responsabilidad, de creación y de esperanza para la colectividad humana. Los testimonios de los campesinos están allí para recordárnoslo. 